\title{
LES IL.LUSTRACIONS DEL MANUSCRIT VAT. LAT. 5730 I LA SEVA RELACIO AMB ALTRES PRODUCCIONS CATALANES DE L'ENTORN DEL $1100^{1}$
}

\author{
ANNA ORRIOLS I Alsina \\ Universitat Autonoma (Barcelona)
}

\begin{abstract}
SUMARI
1. Descripció del manuscrit.- 2. Aspectes iconogräics i formals.- 3. Conclusió.
\end{abstract}

A la Biblioteca Apostolica Vaticana es conserva, sota la signatura Lat. 5730, un manuscrit il.lustrat d'època romànica i de procedencia catalana. Es tracta d'un Comentari a les Eptstoles de sant Pau, atribuït a Sant Agust P $^{2}$. El manuscrit fou donat a coneixer per l'eminent historiador i bi-

'Aquest estudi ha estat realitzat en bona mesura en virtut de la beca atorgada per la Fundació Caixa de Barcelona (Convocatòria d'ajuts a la Recerca 1989. Àmbit Patrimoni Històrico Arqueold̀gic). També vull fer constar el meu agraïment al professor Joaquín Yarza per la seva atenció en relació a aquest estudi.

${ }^{2}$ De fet, es tracta d'una obra apocrifa, ja que la seva redacció no es deu al bisbe d'Hipona ni tampoc, com al mateix manuscrit s'insinua, a Pere de Tripoli, sinó a Flons de Lyon. Sobre aquesta qüestió, vegeu Dom Joseph LEMARIE, Le Bréviaire de Ripoll. Paris, B.N. Lat. 742. Ertude sur sa composition et ses textes inédits, Publicacions de l'Abadia de Montserrat ("Studia et Documenta" 14), Montserrat 1965, pp. 28-30. L'autor fa un estudi paleogrdfic comparatiu del Breviari i del manuscrit que ens ocupa i assenyala la definitiva atribució del text a Florus de Lyon, segons ho demostren diversos estudis precedents (cf. nota 25 de Lemarie).

L'atribució a Pere de Trípoli també es recull a l'inventari manuscrit realitzat el 1627 per A. RANALDI, Inventarium Manuscriptoruin Latinorum Bibliothecae Vaticana. Tomus Sextus, pag. 217.

En relació amb això, desitjo que consti el meu agraïment al doctor Manuel Mundó per la indicació que em féu del parentiu paleografic existent entre el breviari conservat a París i el manuscrit que aquí s'estudia.

"Anuario de Batudion Modiovales", 24 (1994) 
bliotecari, que seria prefecte de la Biblioteca Vaticana, Anselm Albareda ${ }^{3}$. A partir de llavors hom inclogué en estudis globals sobre manuscrits il.lustrats catalans del perfode, on les referències eren forçosament breus i les aportacions poques ${ }^{4}$. Fins a dates relativament recents hom no retornaria al seu estudis.

Actualment sembla haver-hi acord en atribuir el manuscrit a la primera meitat del segle XII, malgrat que en principi se'l va fer de la centúria anterior ${ }^{6}$. En canvi, és del tot unànime l'opinió de considerar-lo ripollès

${ }^{3}$ Anselm Maria ALbaredA, Els manuscrits de la Biblioteca Vaticana Reg. Lat. 123, Vat. Lat. 5730 i el scriptorium de Santa Maria de Ripoll, "Catalonia Monastica" I (1927), pp. 23. 96 i 326-330 (Miscel.lània documental). Aquest va ser el primer estudi i descripció de l'obra. Encara avui (ja ho feia Albareda aleshores, vid.. pàg. 71) s'espera l'aparició del volum dels Codices Vaticani Latini (en curs de publicació) que inclogui aquest manuscrit.

4Josep GUdIOL I CUNILL, Els Primitius. Tercera part. els llibres il.luminats ("La Pintura Medieval Catalana" III), Barcelona 1955, pp. 115-117 (que li dóna erròniament la signatura 5780). Pere Bohigas, la ilustración y la decoración del libro manuscrito en Cataluña. Contribución al estudio de la historia de la ininiatura catalana, vol. I, Periodo románico, Asociación de Bibliófilos de Barcelona, 1960, p. 60 i fig. 20 (p. 59). ID., Les demiers temps de l'enluminure romane en Catalogne: la transition en gothique, "Les Cahiers de Saint-Michel de Cuxa" 5 (1974), p. 42. Cal afegir a aquests estudis l'anàlisi comparativa que en fa des del punt de vista codicològic LEMARIÉ (vid. nota 1).

${ }^{5} \mathrm{Ha}$ estat Maria Eugenia IBARBURU qui, arran dels seus estudis sobre els escriptoris de Vic i Ripoll, ha analitzat les il.lustracions del Comentari, més profundament que no ho féu en el seu dia Albareda, tot definint-ne el context estilistic $i$ incidint en alguns aspectes iconografics, vid. M.E. IbARBURU AsURmendi, Expositio Epistolarium [sic] Pauli Apostoli, de Sant Agusti, a El Ripollès ("Catalunya Romànica" X), Fundació Enciclopèdia Catalana, Barcelona, 1987, pp. 328-332. Posteriorment a: id., La ininiatura románica catalana: Los scriptoria de Ripoll y Vic, Tesi doctoral microfitxada, Universitat de Barcelona 1988, vol. I, pp. 293-313.

Poc abans, però, Núria de DALMASES i Antoni JosÉ I PITARCH (Els inicis i l'art romànic. S. IX-XII ("Història de l'Art Catalä" I), Edicions 62, Barcelona, 1986, pp. 267-269 cito per la segona edició, del 1988-) hi dedicaven unes pàgines on relacionaven les il.lustracions del Vat. lat. 5730 amb les d'altres manuscrits catalans. I cal tenir presents les referències que hi fa A.M. MUNDO a les dues erudites $\mathrm{i}$ utilíssimes visions panoràmiques que són Importación, exportación y expolicaciones de códices en Cataluña (siglos VIII al XIII), al Coloquio sobre circulación de códices y escritos entre Europa y la Península en los siglos VIII-XIII. 16-19 septiembre 1982. Actas, Universidad de Santiago de Compostela, 1988, pp. 87-134 (especialment 131-132) i La cultura artistica escrita, al volum primer de "Catalunya Romànica" (Introducció general), Fundació Enciclopèdia Catalana, Barcelona 1994, pp. 133. 162 (especialment 145).

${ }^{6}$ AlBaREDA, op. cit. (pp. 70 i 72), el considerà de mitjan segle XI, datació que recollí GUdIOL (Els primitius., p. 115). Seria BOHIGAS (La ilustración, pàg. 60 i Les demiers temps, p. 42) qui avançaria la cronologia fins al primer quart del XII. M.E. IBARBURU també es mostrava partidària d'una data inclosa dins de la primera meitat del XII (Expositio, pp. 328 i 330-331; La miniatura, pp. 293 i 305), tot fent algunes puntualitzacions a partir de paral.lels que estableix i sobre els quals tomarem més endavant. DALMASES i JOSÊ (Els inicis, p. 269) prefereixen un marge entre finals de l'XI i principis del XII, tot semblant decantar-se per la data més alta. MUNDÓ (Importación, exportación, p. 131 i La cultura artística escrita, p. 145) el fa també del primer quart del XII. 
d'ençà que aixi ho afirmà Albareda basant-se en el document que apareix copiat als fols. 233 v.-224 (els darrers del volum) i que recull una confirmacio del monarca franc Lotari de les donacions fetes al monestir de Santa Maria de Ripoll l'any $982^{7}$.

A banda de les consideracions de caire cronologic i codicologic, el meu interès se centra principalment el vessant estilístic de les il.lustracions del Vat. Lat. 5730, especialment a partir de les semblances que presenta amb les de l'anomenat Beatus de Tori (Torino, Biblioteca Nazionale, ms. I.II.1), realitzat a Girona pels volts del 1100, tot seguint el model d'un de lleonès del 975 que ja es trobava aleshores a la ciutat, on encara avui es conserva, i de la qual pren el nom ${ }^{8}$.

Admeses les similituds existents entre un $i$ altre manuscrit ${ }^{9}, i$ abans d'analitzar les il.lustracions del de la Vaticana, ens encarem a la qüestio de l'scriptorium. Va quedar demostrat en el seu dia el naixement gironi del Beatus de Tor ${ }^{10}$. Pel que fa al Vat. lat. 5730, ja assenyalava el convenciment del seu origen ripolles per part de tots els autors que s'hi han referit. L'argument era la ja al.ludida transcripció d'un document de confirmació

\footnotetext{
${ }^{7}$ ALBAREDA el transcriu a L'emperador Lotari confirma les donacions fetes al monestir de Sta. Maria de Ripoll, com a miscel.lània documental que acompanya el seu estudi (op. cil., pp. 326-330). Un mateix document aparegué transcrit a la Marca Hispanica, apèndix CXXXI, cols. 929-931, tot indicant-s'hi que s'havia copiat eex chartulario monasterii Rivipullensis». La mà que l'ha copiat al Vat. Lat. 5730, tot $i$ no ser cap de les que intervenen en el text de la resta del manuscrit, es considera contemporània a aquelles (Bohigas, però, precisa que és un xic posterior, vid. La ilustración, pàg. 60). Si existí alguna anotació acompanyant el text, ha desaparegut, atès que el fol. 234 upareix retallat, i se n'ha respectat només un quart que conté la part final de la transcripció. ALBAREDA (ibid., p. 70), creu que és probable que amb això hom s'endugués la signatura i la data.

${ }^{8}$ Fou Bohigas el primer d'assenyalar les similituds existents entre els rostres dels personatges d'un i altre manuscrit, no pas a la seva obra de conjunt sinó en el breu excurs pronunciat als cursos de Cuixà (Les derniers temps, p. 42). Els autors que posterionnent han fet referència al manuscrit vaticà han insistit també sobre el tema (vid. supra, nota 5). Joaquín YARZA també se'n feia ressò, considerant l'existència d'estretes relacions entre ambdues obres (La Miniatura Románica en España. Estado de la Cuestión, "Anuario del Departamento de Teoría e Historia del Arte" (Univcrsidad Autónoma de Madrid), II (1990), pp. 9-25). Recentment, A.M. MUNDÓ (La cultura artistica, p. 145), assenyalava també aquest parentiu estilistic.

${ }^{9} \mathrm{M}$.E. Ibarburu les descriu detalladament en els seus estudis (vid. supra, nota 5), tot estenent els paral.lels als motius ornamentals.

${ }^{10}$ Sobre el Beatus de Torí, dues aproximacions recents són: Constanza SEGRE MONTEL, I manoscritti miniati della Biblioteca Nazionale di Torino, I, Mollese, Torino 1980, núm. 68 del catàleg, pp. 70-76, figs. 207-219 i làm. III), i Maria Eugenia IBARBURU ASURMENDI, Beatus de Tori, a El Girones. La Setva. El Pla de l'Estany ("Catalunya Romànica" V), Fundació Enciclopèdia Catalana, Barcelona, 1991, pp. 131-141. Ambdós inclouen un estat de la qüestió sobre l'estudi del manuscrit.
} 
de béns de l'abadia de Santa Maria de Ripoll que es troba al darrer foli del manuscrit vaticà. És prou sabut, pero, que pràctiques d'aquest tipus (és a dir, afegir algun text a un manuscrit preexistent) eren freqüents a l'epoca i, si bé són indicis valuosos, l'únic que fan és confirmar l'indret on es trobava el manuscrit en un moment determinat, la qual cosa no ha d'implicar necessàriament que fos realitzat allr. En el cas del manuscrit que ens ocupa, doncs, podria tractar-se d'una obra no nascuda a Ripoll i traslladada all poc després de la seva realització? ${ }^{11}$. Haig de reconeixer aqur, d'una ban$\mathrm{da}$, el meu interes a fer l'obra gironina, per tal de contribuir aix 1 a definir el taller d'il.lustradors que sens dubte treballa alls entre finals de l'XI i principis del XII, pero cal admetre també algun argument en favor de Ripoll pero sense perdre de vista, tanmateix, el fort poder d'atracció que ofereix l'abadia a l'hora d'atribuir obres al seu scriptorium. Valgui, a tall d'exemple, el cas de dos manuscrits prou coneguts la factura ripollesa dels quals ha estat, totalment o parcialment, qüestionada: la Bíblia de Rodes (Paris, Bibliotheque Nationale, ms. lat. 6) i el Reginensis Latinus 123 de la Biblioteca Apostolica Vaticana, amb textos i il.lustracions de temàtica astronòmica, de l'any 1056. Pel que fa a aquest darrer, d'ençà del finals del segle passat, es van alternant les atribucions a Santa Maria de Ripoll i a Sant Victor de Marsella ${ }^{12}$. Precisament s'ha considerat que el codex astronomic, el de les epistoles paulines i la Biblia de Ripoll haurien estat llevats de Ripoll per monjos marsellesos quan el 1180 es va acabar la subjeccio del cenobi catala respecte del provençal ${ }^{13}$.

Quant a la Bßblia de Rodes, pràcticament sempre se l'ha considerada ripollesa, tot i prendre el nom del monestir empordanes on féu innegable i llarga estada d'ençà del segle XII (com ho confirma una butlla del papa

\footnotetext{
"Recordem -vid. nota 7- que la mà que copia el document de confinnació, si bé contemporània, és diferent $\mathrm{i}$ un xic posterior a les que copien el text de l'Expositio Epistolarum Pauli Aposioli. Tampoc no cal oblidar que Pèire de Marca declarava haver copiat la confirmació aex chartulario monasterii Rivipullensis».

${ }^{12}$ En relació al Vat. Reg. 123, cf. un breu estat de la qüestió sobre el tema a M.E. IBARBURU ASURMENDI, La pervivencia de ilustraciones sobre temas astronómicos del mundo clásico en manuscrilos románicos, a través del ins. Vat. Reg. 123, a V Congrés Espanyol d'Histdria de l'Art (Barcelona 29 oct.-3 nov. 1984), vol. I, Barcelona, 1986, pp. 29-37, on l'autora el considera de nou ripolles. A.M. MUNDÓ, Importación, exportación, pp. 131-132, que igualment ofereix una quaestio disputata a la nodrida nota $134 \mathrm{i}$ considera que el Reg. lat. 123 fou escrit amb seguretat a Ripoll.

${ }^{13} \mathrm{Ja}$ Albareda, op. cit. (p. 77) cridava l'atenció sobre la correlació de signatures existents entre la Bíblia de Ripoll (Vat. lat. 5729) i el comentari a les epistoles de Pau (Vat. lat. 5730), fet que també emfasitza Mundó (vegeu nota anterior).
} 
Innocenci II en favor de Sant Pere de Rodes amb data del 1130, copiada al foli 39 del vol. III ) fins al segle XVII en que fou rapinyada pel mariscal Noailles. Cal observar d'altra banda com ens trobem davant d'un dels casos comentats d'inserció de la còpia d'un document en un manuscrit de procedencia, en aquest cas, innegablement forana ${ }^{14}$.

Sense pretendre qüestionar, ni de bon tros, la importancia de Santa Maria de Ripoll i del seu scriptorium, sí que voldria remarcar una sèrie de circumstàncies vinculades al monestir que poden haver condicionat algunes valoracions sobre la producció de manuscrits d'alli sorgida: la relació amb personatges gairebé "mítics", començant pel mateix fundador Guifré el Pelós, o el que seria papa del mil.lenni, Gerbert d'Aurillac, i arribant a l'abat i bisbe Oliba; la possessió d'una molt nodrida biblioteca -de la qual, a més, se'n coneixen inventaris-; el fet d'haver estat lloc d'enterrament de comtes del casal de Barcelona; l'actual conservació d'un notable patrimoni monumental; el gaudir d'una extensa bibliografia de molt de temps ençà... Tota obra d'una certa envergadura, per petit que en sigui l'indici, es pretén ripollesa. On s'hauria adscrit el Beatus de Torí si no s'hagués pogut demostrar que és gironi? ${ }^{15}$ Obres com aquesta, com l'anomenat Homiliari de Be-

\footnotetext{
${ }^{14}$ Estudis recents que repassen la historiografia sobre la Biblia de Rodes i l'escriptori ripollès són els de Rosa ALCOY I PEDRÓS, Biblia de Rodes, a El Ripollès ("Catalunya Romànica", X), Fundació Enciclopèdia Catalana, Barcelona, 1987, pp. 292-305 i de M.E. IBARBURU, Bßblia de Sant Pere de Rodes, al catàleg de l'exposició Catalunya Medieval, Bancelona, 1992, núm. 1.21, p. 58. Una visió global de l'scriptorium de Ripoll des dels seus inicis i on es fa referència, entre d'altres, als dos casos que aquí comentem, és la de Mathias DELCOR, Le Scriptorium de Ripoll et son Rayonnement culturel. État de la question, "Les Cahiers de SaintMichel de Cuxa", 5 (1974), pp. 45-64. Peró sobre la possible intervenció d'un scriptorium ubicat a Sant Pere de Rodes, on s'hauria pogut il.lustrar part de l'obra, és fonamental Peter KLEIN, Date et scriptoriuin de la Bible de Roda. État des recherches, "Les Cahiers de SaintMichel de Cuxa", 3 (1972), pp. 91-102. Quan Klein va publicar el seu estudi era hipotètica l'existencia d'un escriptori a Rodes. Ara ja ha deixat de ser-ho, perque hi ha proves de la seva activitat. Vid. Jesús ALTURO I PERUCHO, Un inanuscrit du scriptoriuin de Sant Pere de Rodes (Catalogne): le "Tractatus in Iohannem, de saint Augustin. "Revuc des Études Augustiniennes", 39 (1993), pp. 155-160. D’altra handa, MUNDS (La cultura artística, pp. 139-140) també considera que les il.lustracions de l'Apocalipsi de la Biblia de Rodes (actualment volum IV) devien ser realitzades al monestir empordanès.

${ }^{15}$ Sobta trobar, en una obra força recent $i$ deguda a un autor amb dilatada $i$ prolifica trajectòria en l'estudi de la miniatura medicval, una explícita atribució del Beatus a l'scripıorium de Ripoll. Vid. François AVRL, Les arts de la couleur, a Le monde roman, II. Les Royaumes d'Occident ("L'Univers des Fonnes"), Gallimard, Paris, 1983, pp. 159-259. Hoin hi pot llegir: aL'oeuvre la plus ambiticuse sortic du scriptorium de Ripoll à cette époque est un Beatus de la Bibliothèque Nationale de Turin.... (p. 244). Una petita relliscada si tenim en compte que, en la que havia de ser l'obra definitiva sobre els bealus il.lustrats -apareguda, després de moltes dilacions, el juny del 1994- l'autor ("one of the most renowned scholar in the field", segons llegim a la solupa de la sobrecoberta del volum) indica com a lloc d'origen
} 
da (Museu d'Art de Girona, núm. inv., 56), la possibilitat que els volums III i IV de la Biblia de Rodes s'il.lustressin, en moments diferents, fora de l'abadia ${ }^{16}$, o l'existència del poc estudiat encara Evangeliari de Cuixa (Perpinya, Bibliotheque Municipale, ms. 1), desplacen el centre de gravetat de la il.lustració de manuscrits fora de Ripoll, sobretot cap a terres gironines i empordaneses. Totes aquestes obres, d'altra banda, presenten, sense oblidar logics contactes amb produccions ripolleses i vigatanes, una certa homogeneïtat entre si, tant a nivell estilístic com cronologic. I aixo darrer també mereix comentari. Ens movem en unes dates que, des del segle XI o dins del següent, s'aproximen al 1100 . I, arribats aqui, cal no oblidar que si bé els abadiats d'Arnulf (948-970) i d'Oliba (1008-1046) suposaren etapes brillants per al cenobi tant a nivell intel.lectual com artístic (i és precisament aleshores quan es començaren les bŕblies de Ripoll i de Rodes -independentment que la il.lustració d'aquesta darrera s'hi culminés o no-), no es pot dir el mateix dels cent anys següents, durant els quals el monestir passà per mals moments, que inclogueren la seva supeditació a l'abadia de Sant Victor de Marsella ${ }^{17}$. Aquesta dependencia, iniciada el 1070, no s'acabaria definitivament fins el 1180 , després d'un procés iniciat poc abans de mitjan segle, per tal de desfer-se del lligam i on confluïren diverses voluntats i es posaren les empreses artístiques (la magnifica portalada, que sembla haver estat el cant del cigne de la historia artística de l'abadia) al servei d'uns interessos determinats ${ }^{18}$.

Sense oblidar la riquesa de la biblioteca (constatable a través de diversos inventaris coneguts), i tampoc l'incendi que el 1835 posà fi a bona part del seu fons, o l'espoli de que pogués haver estat víctima molt temps

d'aquella obra "probably Ripoll". M'estic referint a John WILJIAMS, The Illustrated Beatus. A Corpus of the Illustrations of the Commentary on the Apocalypse, vol. I, Introduction, Harvey Miller, London, 1994, p. 11.

${ }^{16}$ Vid. nota 14.

"Vid. Eduard Junyent, El inonestir de Santa Maria de Ripoll, Barcelona, 1975, per a una síntesi de la història del monestir.

${ }^{18}$ Aquest procés d'utilització de la portada com a medi propagador d'uns valors que interessaven l'abadia $i$ el casal de Barcelona ha estat analitzat per J. YARZA LUACES en el capítol Lectura iconogràfica; programa religiós aimb component polític, dins de l'estudi sobre la portalada esculpida de Ripoll a El Ripolles ("Catalunya Romànica" X), pp. 245 ss. Posteriorment, ja al tombant de segle, s'escomctria la tasca del claustre, però aquest no tingué prou empenta per acabar-se. D'altra banda res, ni a nivell formal (derivació de les ja esgotades formes rosselloneses) ni iconogràfic (absència d'un programa, reiteració de fórmules) pot parangonar-se a la impactant portalada. Sobre el claustre, vegeu el capítol que hi dedica X.Barral i Altet, en l'estudi citat més amunt, pp. 252-257. 
abans per part de monjos marsellesos, la impressió que hom té a la llum del que ha estat conservat és que la quantitat i qualitat de les il.lustracions de manuscrits davallen a l'epoca posterior a Oliba ${ }^{19}$. Aquf cal retornar al Vat. lat. $5730 \mathrm{amb}$ el comentari a les epístoles paulines: a part del Beatus de Torí, és una de les poques obres amb un cert interès a nivell d'il.lustració (quantitativament molt inferior a la del Beatus, de totes maneres) entre les situables en una franja que va del final de l'XI al primer quart del XII. Ja hem vist com les altres que s'hi poden afegir (i, a més, s'hi poden relacionar estilísticament $\mathrm{i}$ cronologica) no són ripolleses. Tampoc no ho és el Beatus. Davant de tot aixd argumentat fins ara i sense possibilitats, de moment, de provar-ho d'una manera irrefutable, podem pensar que el Vat. Lat. 5730 fos realitzat en un taller no ripolles sinó gironi, més capaç en aquells moments de fer-se càrrec de la copia i de les il.lustracions del manuscrit $\mathrm{i}$ que fos traslladat, poc després o immediatament, a Santa Maria? L'estil de les miniatures podria ben evidenciar-ho. Qüestions paleogràfiques i codicologiques són, per ara, de relatiu ajut, si bé no van en contra del que aquf suggerim ${ }^{20}$. El colofó del Vat. Lat. 5730 és tan dificultós de llegir com poc explícit ${ }^{21}$. A la copia del text hi intervenen diverses mans de

${ }^{19} \mathrm{cf}$. M. DELCOR, Le Scriptoriuin de Ripoll, pp. 54-55. De fet, aquesta situació ja s'assenyalava en estudis pioners de l'abadia, com el de Rudolf BEER, Die Handschrifien des Klosters Santa Maria de Ripoll, Viena, 1907-1908 (uso i cito la traducció catalana de Pere Bamils i Giol publicada per entregues al "Boletín de la Real Academia de Buenas Letras de Barcelona", V-36/40 (1909-1910), que també aparegué en un volum a part com a separata, Estampa de la Casa de la Caritat, Barcelona 1910); cf. 2a. part, 3a. entrega ("Boletín de la Real Academia de Buenas Letras de Barcelona", núın. 38 (abr.-juny 1910), pp. 307-314).

${ }^{20} \mathrm{Mn}$. Gabriel Roura, cap de l'Arxiu Capitular de Girona i que actualment treballa en la seva tesi doctoral sobre els escribes d'aquella catedral en aquest periode, un cop examinat el text del manuscrit, considera que no hi ha res a la seva cal.ligrafia que resulti estrany a l'escriptori de Girona. Malgrat això, li manquen indicis irrefutables per a afirmar amb rotunditat tal procedencia, sobretot per la homogeneïtat de la minúscula carolina emprada en escriptoris com Vic, Ripoll i Girona.

${ }^{21}$ Les majúscules, pintades a mosaic, semblen fruit d'una perversa voluntat de dificultar-ne la lectura. Amb tot, pot arribar-se a transcriure aquest colofó, on l'escriba no s'identifica ni signa, sinó que es limita a una sèrie de fórmules laudatòries. La transcripció en seria la següent: FINIT AUREUI AUGUSTINI TRACTATUS AEPISCOPI / SUPER EXPOSITIONE AEPISTOLARUM APOSTOL PAUU / CONDITUS HIC CODEX DINOSCITUR OPITMA TESTANS / SUSCRIPTOR METAM PONENS IN SALCE LABORIS / PROUECTU GAUDENS PLACIDO GRATIATUR ONORE / GAUDEATIS LONGE PRESENTI LUMINE FELIX / ET SEMPER LETANS LETAETUR TEMPORE CUNCTO. Malgrat l'absencia de revelacions pel que fa a dades, potser el tipus de text o d'escriptura pot aportar alguna informació. Vull agrair a Marc Torras i Scrra, responsable de l'Arxiu Municipal de Manresa, i sobretot a Mn. Gabriel Roura, cap de l'Arxiu Capitular de Girona, el seu inestimable ajut en tan difícil lectura. Consti també el meu agraïment al Dr. José Martínez Gázquez, de la Universitat Autònoma de Barcelona. 
qualitat diversa, una de les quals sembla haver estat la mateixa que treballa en un Breviari benedictl que s'ha considerat ripolles (Paris, Bibliotheque Nationale, lat. 742), la qual cosa, en cas de ser certa, aniria en contra de la nostra proposta. Però no és tot tan clar. Cal no oblidar que l'atribució de l'esmentat Breviari a l'scriptorium de Ripoll es deu a una suposició de Lemarié basada precisament en les similituds a nivell paleografic amb el nostre $\operatorname{codex}^{22}$.

\section{DESCRIPCIÓ DEL MANUSCRIT}

De grandària considerable $(476 \times 364 \mathrm{~mm})^{23}$, el volum consta de 234 folis repartits en 29 quaderns més dos folis en blanc al final i un de guarda al començament (alie al manuscrit, i amb lletra d'epoca posterior). És escrit a dues columnes, amb lletra carolina, i a l'escriptura es detecten diverses mans. Es conserva complet $i$ en bon estat, enquadernat en fusta $i$ pell amb les armes de Gregori XV (1621-1623) ${ }^{24}$.

Les titulars són majúscules i pintades a mosaic. Catorze caplletres il.lustrades repartides al llarg del manuscrit decoren l'inici dels diversos

\footnotetext{
${ }^{22} \mathrm{Cal}$ no confondre aquest manuscrit amb el Breviarium de Musica (Arxiu de la Corona d'Aragó: Ms. Ripoll 42). Segons el parer de J. LEMARIÉ, Le bréviaire, pp. 29-30, un mateix copista hauria executat els fols. 182 v.-192 v. del manuscrit de la Vaticana i la totalitat del Breviari conservat a París. Aquesta comunitat de mans hauria estat corroborada per altres paledgrafs, com ara Bohigas i Mundó (vid. ibid., p. 10). Cronològicament el situen entre $1110-1140$.

La procedència del còdex, desproveït de particularitats que la puguin revelar, havia estat anteriorment fixada en terres del midi francès. Victor LEROQUAIS (Les Bréviaires manuscrits des bibliotheques publiques de France, II, Paris, 1934, pp. 417-418) afirmava que la notació neumàtica assenyalava l'escola aquitana. El mateix Lemarié, en un principi, el cregué marselles, ja que les peculiaritats litúrgiques que s'hi detectaven eren comunes a les presents en breviaris de Marsella $i$ d'altres indrets del midi. Finalment arribava a la conclusió que havia de provenir d'una abadia d'una certa importància vinculada a la reforma de Sant Víctor de Marsella (vid. Lemarié, Le bréviaire, pp. 8-9). Per un procés d'eliminació d'altres cenobis acabava quedant-se amb Ripoll, peño sense proves. Aquestes les obtindria en constatar la comunitat de mans abans comentada entre el breviari i el Vat. Lat. 5730 ("La question d'origine du manuscrit, insoluble sur le plan de l'analyse liturgique, se trouvait résolue gráce a l'analyse paléographique", ibid., p. 10). Precisament, doncs, fa ripolles el breviari a partir d'una obra que aquí suggerim que tal vegada no ho sigui.

${ }^{23}$ Devia ser un xic més gran a l'origen, i probablement amb motiu de la posterior enquademació, va tallar-se. Al foli $203 v$ hom pot apreciar que fou retallat un centímetre a la vora superior del manuscrit.
}

${ }^{24}$ Mes detalls codicoldogics i paleografics es troben a ALBAREDA, Dos manuscrits de la Biblioteca Vaticana, pp. 70-71 i a LEMARIE, Le Bréviaire, pp. 28-30. 
capítols. Llevat d'una $M$ (encapçalant l'epístola als Hebreus, fol. 218) ${ }^{25}$, totes les altres són PP (corresponents totes aquestes al mot Paulus). Resulten cridaners els colors, vius i nítids, sobretot en comparació amb bona part de la il.lustració de llibres catalana d'epoca contemporània i anterior. Hi predominen verds, vermells, blaus i grocs; per a les carnacions s'emprà un rosat molt pàl.lid; algunes vegades es recorre també al carbassa, a un lila rosat viu i al marró rogenc destinat sempre a cabells i barbes dels personatges. Les tintes són espesses, característica comuna a les il.lustracions del Beatus de Torı, si bé en aquest darrer és menor la presencia del verd i freqüent la del carbassa; en general, els colors són més apagats que en al Vat. lat. $5730^{26}$.

En totes les caplletres s'ha usat un recurs que constitueix el fons i a la vegada l'emmarcament de les composicions, tot resseguint-les externament, tancant-les en una forma de múltiples angles rectes, unes vegades monocroma, i unes altres amb franges multicolors.

En tots els casos es combinen formes vegetals amb elements humans o zoomorfics. A vegades són testes d'animal, però són més freqüents els quadrúpedes, tot sovint alats, i els dracs, de les boques dels quals solen sorgir tiges, o que semblen mossegar-se entre ells o bé els personatges (fig. 1). Aquests es contorsionen tot formant part de la caplletra, la subjecten a manera d'atlants o be, uns altres de mida més petita, en recorren les diverses parts en actituds lúdiques. Gairebé sempre vestits, només dues figures més menudes (l'una proveïda d'una cua) van nues. Nua de mig cos és una cridanera figura femenina en actitud d'atlant al fol. 209 v. (fig. 2). Només hi ha tres caplletres que han prescindit de la figura humana. Un parell de personatges duen una falç (fols. 67 -fig. 1 - i 217 v., molt mal resolta aquesta darrera) i la resta, o bé en la seva posicio d'atlants sostenen la panxa

\footnotetext{
${ }^{25}$ A l'estudi d'Albareda citat (nota 3), s'inclouen totes les il.lustracions d'aquest manuscrit.

${ }^{26}{ }^{2}$ s probable que l'incendi que la nit del 26 de gener del 1904, que tant va malmetre el fons de la biblioteca quan aquesta encara es trobava a les dependències del Palazzo dell'Universita a Via Po, i l'aigua que es va emprar per a sufocar-lo afectessin els colors del manuscrit. El Beatus encara avui presenta mostres de l'acció del foc als marges dels seus folis, penó no fou pas un dels manuscrits més perjudicats per les flames, tot i que les nombroses taques degudes a l'aigua presents en els scus folis podrien fer pensar en una modificació dels colors. Vid. un detalladissim seguiment de la catàstrofe i posteriors restauracions de les obres a Manoscritti danneggiati nell'incendio del 1904. Mostra di recuperi e restauri, Biblioteca Nazionale Universitaria di Torino, febrer-març 1986, catàleg a cura d'Angelo GiACCARIA, Torino, 1986. Encara que el Beatus no formés part de l'Exposició, a l'estudi que acompanya l'esmentat cataleg es veuen reflectides les vicissituds per les quals passà, i hom es fa una idea del tipus de danys que sofriren els codexs.
} 
de la lletra o be subjecten tiges o cossos dels quadrúpedes. Una munió de gests i d'actituds, més remarcable encara si hom té en compte la monotonia que ofereix el patro omnipresent de la lletra $P$, i que donen, juntament amb la vivesa del color $\mathrm{i}$ els rostres caricaturescs d'alguns dels personatges, un cert caràcter bulliciós a les il.lustracions.

Sembla una sola mà la que ha executat totes les il.lustracions, si bé resulta diffcil d'explicar la poquissima fortuna amb que ha estat traçat el personatge del f. 1v, en gest que calca el del fol. 192. L'artista demostra tenir un traç segur i una certa agilitat en algunes de les composicions, encara que en conjunt el seu treball no sigui d'una gran qualitat.

\section{ASPECTES ICONOGRÀFICS I FORMALS}

Entre les catorze il.lustracions, destaca la $P$ del fol. 175 v. (fig. 3), que encapçala l'epístola als Filipencs amb els mots "Paulus et Timotheus, servi Jesu Christi..." on, en consonància amb aixd, s'han representat dins la panxa de la lletra les figures de Sant Pau, amb la calba caracteristica i sostenint un llibre, i un personatge d'aspecte més jove, igualment nimbat, sens dubte el seu deixeble Timoteu. El pal de la lletra, pero, és de nou dominat per la fauna fantàstica.

Es molt probable que la figura femenina que actua com a cariatide a la P del foli 209 v. (fig. 2), per la nuesa del tors, la llarga cabellera i la rotunditat dels pits, al.ludeixi de forma més o menys directa a la Luxúria. Encapçala el comentari a la Segona Epistola a Timoteu, on Sant Pau (IITm 3, 1-9) anuncia temps d'immoralitat i d'impietat, $i$ al.ludeix a unes "...dones carregades de pecats, agitades per passions de tota mena". Abans ha advertit contra els "amants del plaer més que no pas de Déu"27. Sant Pau com també nombrosos autors que el prendran com a punt de referència (sant Ambros, sant Agustr...), consideren la dona com a desencadenant del pecat $^{28}$. És obvi, doncs, que sota aquests plantejaments la imatge de la

\footnotetext{
${ }^{27}$ M.E. Ibarburu, que pel que fa als aspectes iconografics del manuscrit es concentra sobretot en aquesta figura, acaba considerant que es tracta més aviat d' "una utilització a nivell exclusivament fornal o compositiu d'un model probablement relacionat amb la luxúria, però mancat d'una voluntat conscient d'il.lustrar un text concret" (Expositio Epistolarum, p. 329).

${ }^{22}$ La misogínia omnipresent en cls textos patrístics $i$ els dels posterions autors cristians $-i$ que també es detecta en els clàssics- no deixa dubtes respecte d'això: la dona és el principi de tos els mals. Cal, en aquest punt, referir-se sens dubte a l'estudi de Marie-Thérèse d'AL-
} 
Luxúria requereixi la figura femenina; i no cal que l'acompanyin atributs especffics per tal que la identificació sigui possible ${ }^{29}$. Al Vat. lat. 5730 probablement no es tracta tant d'una representació explícita de la Luxúria com d'una al.lusió generica al pecat, a la immoralitat a la qual fa referencia l'Epístola. I allo que em sembla evident és que no s'ha desaprofitat l'ocasio per a recórrer a una imatge voluptuosa, font a la vegada de desig i de pecat, una d'aquelles fatals atraccions ${ }^{30}$.

A part d'aquests dos exemples comentats, dubto que les caplletres restants hagin estat concebudes en relacio a la redaccio que acompanyen. La comparacio amb d'altres textos paulins il.lustrats ofereix molt poc joc $^{31}$. Entre els manuscrits catalans romànics, hi ha el cas d'un exemplar il.lustrat de les Epístoles de Sant Pau (ms. 158 de la Biblioteca Pública de Tarragona), procedent de Santes Creus i que podria ser del final del XII, poc notable a nivell de figuracio $6^{32}$. Els cicles neotestamentaris podrien ser

VERNY, Coınınent les théologiens et les philosophes voient la femıne, "Cahiers de Civilisation Médiévale", XX-78/79 (1977), pp. $105-129$ (cspccialınent, pp. 107-111 pcl què fa a sant Pau) i a la patristica, als quals els autors postcriors es referiran repetidainent.

${ }^{29}$ El cos femení per si sol encarna la Luxúria. I, en concret, els pits i la cabellera esparsa en són trets caracteritzadors. Vid. Chiara FRUGONI, L'iconographie de la femune au cours des Xe-XIIe siecles, "Cahiers de civilisation Médićvale" XX/78-79 (1977), pp. 177-188 (especialment 180-181); i el classic Adolf KATZENELLENBOGEN, Allegories of the virtues and Vices in Medieval Art, publicat pel Warburg Institute de Londres el 1939 i que ha estat objecte de diverses reimpressions.

${ }^{30}$ És allo que Frugoni (vid. nota anterior) defineix coin l'expressió d'una "...'scission précise' du vouloir de l'hoınme, du religieux, qui désire et repousse à la fois l'objet de son désir et de son péché" (p. 180).

${ }^{31}$ A.M. Mundó ha assenyalat en alguna ocasió (La cultura artistica, p. 145) la germanor textual i decorativa existent entre el Vat. Lat. 5730 i un altre comentari de Florus de Lió a les epistoles paulines, escrit i il.lustrat a l'abadia de la Grassa i ara conservat a Nîmes (Bibliotheque Municipale, ıns. 36). Si bé el text és coınú, goso discrepar-ne pel que fa al parentiu de les il.lustracions. El manuscrit de la Grassa, les il.lustracions del qual Schapiro va relacionar amb escultures de la portada de Saint-Gilles-du-Gard, és estilisticament prou divers del vatica. Hi pot haver una remota coincidéncia compositiva pel fel d'il.lustrar-se pràcticament sempre una caplletra $P$, però iconograficament un i altre repertori il.lustratiu no es deixen agernanar. Hom pot trobar indicada la bibliografia sobre el codex a De Toulouse d Tripoli. La puissance toulousaine au XIle siécle (1080-1208), catàleg exposició, Musée des Augustins (6 janvier - 20 mars 1989), Toulouse, 1989, p. 228 (núm. 333). Per a la discussió sobre la relacio amb l'escultura de Saint-Gilles, vegeu Whitney S. STODDARD, The Façade of SaintGilles-du-Gard. Its influence on French Sculpture, Weslcyan University, Middletown, Connecticut, 1973, pp. 139-140 i figs. 184-185 (p. 141).

${ }^{32}$ Com a l'Expositio de la Vaticana, les miniatures es limiten a les caplletres, pero l'exemplar tarragoni, a part de ser d'una factura notablcınent tosca, restringcix la figura humana a una sola aparició. Alli, un personatge, des del pal d'una caplletra $P$ subjecta una de les tiges que omplen la panxa de la lletra (fol. 70, il.lustració a P. BOHIGAS, La ilustración y la decoración, fig. 22 i p. 63). La coincidencia d'actitud amb alguns dels personatges del Vat. lat. 
un altre indret on cercar paral.lels, pero de les dues Bíblies il.lustrades catalanes, com és sabut, una, la de Rodes (Paris, Bibliothèque Nationale, ms. lat. 6), conté tan sols algunes il.lustracions de l'Apocalipsi de sant Joan. La de Ripoll (Vat. Lat. 5729) no il.lustra els textos de sant Pau. Les inicials d'una i altra són força simples en la majoria dels casos i no semblen tenir res a veure amb les que ens ocupen ${ }^{33}$.

Caldria recórrer a la il.lustració forània per a trobar exemples de caplletres en relació als textos paulins amb decoració figurada d'una certa entitat, o bé cicles que il.lustrin episodis de la vida de l'apdstol, i que a vegades poden resultar força amplis, tot i que, si acceptem que només una de les nostres caplletres (fol. 175 v.) (fig. 3) té a veure amb el text que acompanya, aquests cicles no ens poden servir de referència ${ }^{34}$.

Es molt comú que les catorze epístoles de Sant Pau s'il.lustrin a partir d'una caplletra, que exceptuant la M (de Multifariam) que inicia l'Epístola als Hebreus, és sempre la inicial del nom de l'apostol. El fet més habitual és després situar a l'interior d'aquestes lletres escenes al.lusives al text en qüestio $\sigma^{35}$. Sovint, aquestes escenes es repeteixen; aixl, és freqüent trobar representat l'episodi de la conversió del sant a partir de la seva caiguda del cavall, o bé trobar-lo assegut davant del faristol escrivint, adreçant-se a un grup de persones, o en companyia d'un deixeble (Timoteu). Tan sols aquest darrer cas és comú amb el Vat. lat. 5730. Aixo ens fa pensar que els il.lustradors del manuscrit, o bé no tenien a l'abast un repertori d'il.lustracions de tamàtica paulina, o que el que posseïen era força limitat, potser reduït a la imatge del sant amb un deixeble, $i$ que es veiessin obligats a servir-se d'uns altres ${ }^{36}$. Tot aix $\delta$ sembla confirmar-se quan es com-

5730 no sembla gaire encoratjadora pel fet, ja assenyalat, de tractar-se d'un motiu extraordinàriament estès dins la miniatura romànica. Sobre el manuscrit de la Biblioteca Pública de Tarragona, a més, J. Domf́nGUEZ BORDONA, El escritorio y la primitiva biblioteca de Santes Creus, Instituto de Estudios Tarraconenses "Ramón Berenguer IV". Excma. Diputación Provincial de Tarragona, Tarragona 1952, p. 116.

${ }^{33} \mathrm{cf}$. M.E. IBARBURU, Expositio epistolaruin, p. 328.

${ }^{34} \mathrm{~L}$ 'àmbit més ben conegut, atès que ha estat objecte d'un estudi monogràfic, és l'inclòs a la il.lustració biblica francesa $i$ anglesa dels segles XII i XIII: Luba ELEEN, The Illustration of the Pauline Epistles in French and English Bibles of the Twelfth and Thirteenth Centuries, Clarendon Press, Oxford 1982. Del mateix autor, $\mathrm{i}$ en un altre ambit, Acts Illustration in Italy and Byzantium, "Dumbarton Oaks Papers", 31 (1977), pp. 253-278.

${ }^{33}$ Només cal repassar les nombroses imatges que acompanyen l'estudi de L. Eleen (vid. nota anterior). La imınensa majoria, peró, són cronològicament posteriors al manuscrit que ens ocupa.

${ }^{36}$ De totes maneres, per a un tipus d'imatge tan genèrica com la d'un sant amb un deixe- 
paren les caplletres del nostre manuscrit amb les d'un Leccionari de la Biblioteca Nacional de París (ms. lat. 794), amb el qual les analogies són força acusades ${ }^{37}$.

En efecte, entre les inicials que decoren el manuscrit de París, en destaquen quatre de més grandària compostes, com al Vat. lat. 5730, per figures humanes, d'animals i fantàstiques. Es tracta també de $P P$, el pal de les quals és format per figures superposades. És igualment coincident el tipus de fons-emmarcament emprat tot resseguint les lletres. Aqui, si cal, l'il.lustrador ha anat encara més enllà en la tria de personatges fantàstics: hi apareixen en dues ocasions (fols. 8 i 170) éssers mixtes, humans de cintura en amunt i equins la resta. Dos més (fols. 29 v. i 71 v.) (fig. 4), completament nus, són mossegats per dracs alats. Hi sovintegen les aus, que no trobàvem al Vat. lat. 5730. Aus de diversa naturalesa: un tipus que recorda el colom, un altre amb llargues potes... El personatge nu del fol. $29 \mathrm{v}$. del Leccionari (fig. 4) és mossegat simultàniament per dos dracs, l'un amb cinc caps, quatre dels quals més petits. És difícil sostreure's a la temptació de comparar-lo amb la bèstia i el dragó apocaliptics que protagonitzen algunes escenes del Beatus de Torf (fols. 131 v.-132, 135), sobretot pel que fa als caparrons que emergeixen dels llargs colls de les bèsties. Fora d'aixd, si bé els personatges, tots representats de perfil, tenen uns trets facials força cridaners, la seva factura és diversa d'aquella tan propia del Beatus, del Vat. Lat. 5730 o de l'Evangeliari de Cuixà. Ens trobem davant d'una obra catalana? O, anant més enllà, del mateix taller? És arriscat respondre, per ara. Pero és cert que un ambient força comú inspira les suggestives caplletres del Vat. lat. $5730 \mathrm{i}$ del Paris $794^{38}$.

ble, no cal recórrer a un cicle específicament pauli. Representacions comunes a les vides de molts sants (predicació a un grup, donació d'una obra, baptisme...) fornen part des d'antic d'un bagatge general que s'adapta a cicles concrets, sense que molts cops sigui necessari introduir-hi cap modificació.

${ }^{37}$ El fet que aquesta obra s'hagi considerat pràcticament scmpre italiana, i en alguna ocasió francesa, juntament amb la circumstància de trobar-sc a Paris, no sembla haver fet adonar-se de les similituds. Aquestes $m$ 'havien cridat l'atenció a través d'alguna il.lustració publicada del manuscrit, i vaig poder comprovar que GUDIOL (E/s primitius, p. 117) ja havia parlat "d'una certa semblança, no identitat" entre les il.lustracions del lat. 794 de Paris i el Vat. lat. 5730. Tambe ho apuntaria Joaquín YARZA, La miniatura roınánica en Esparia, p. 22, insistint-hi més recentment a Beat de Tori, al catàleg de l'exposició Catalunya Medieval, Barcelona, 1992, pp. 82-83, encara que el manuscrit no fou present a la mostra. J. Yarza considera factible relacionar amb l'scriptorium que realiteà el Beatus aquest Leccionari.

${ }^{38}$ Personalment, després d'una primera anàlisi de les il.lustracions del manuscrit de la Biblioteca Nacional de París i la consulta de bibliografia respecte d'això, no goso de moment 
Tenint, perd, present que les il.lustracions del Paris 794 no són del tot alienes a la manera de fer de la il.lustracio de certs scriptoria francesos, un origen o una recepcio d'influencies provinents d'alls tampoc no serien impossibles $^{39}$. De tota manera cal ser caut, perque aquest tipus d'inicials, en que personatges $i$ animals es mouen entremig del fullatge tot configurant les lletres, són freqüents en diversos àmbits de la il.lustració de manuscrits contemporània, fins al punt que podem afirmar que es tracta de motius gairebé genèrics, de repertori, els quals, amb variants, poblen una bona part dels manuscrits romanics occidentals. En efecte, les atractives caplletres d'alguns dels manuscrits realitzats durant l'abadiat de l'anglès Stephen Harding al monestir borgonyó que hauria de ser bressol del més important moviment monàstic del XII, Cîteaux, en són un bon exemple. Pero, encara que el cenobi pogués haver actuat com a difusor en determinat moment d'aquestes fórmules, no en fou el creador. Són ben conegudes obres com la Bßblia del mateix Harding (Dijon, Bibliothèque Municipale, mss. 12-15) enllestida cap al 1109-1111 o els Moralia in Iob de Sant Gregori Magne (Dijon, Bibliotheque Municipale, mss. 168-170 i 173), acabats en bona part el 1111. Tots s'inclouen a l'anomenat "primer estil de Cîteaux" i haurien estat copiats i il.lustrats en el període fundacional del monestir, en un mo-

inclinar-me cap a una postura determinada a favor d'un origen català o italià de l'obra, tot $i$ que cada vegada estic més convençuda d'aquest darrer. Si bé les esmentades quatre caplletres de major grandària criden fortament l'atenció en relació al manuscrit que aquí s'estudia, les altres, molt menys ambicioses, seinblen inés properes a allo italià. I és en aquest àmbit on s'inclou el manuscrit, en els estudis inés recents on ha estat considerat. Vid. F. AVRIL i Y. ZALUSKA, Manuscrits enluminés d'origine italienne, I. Vle-XIle siècles), Bibliothèque Nationale, Paris, 1980. N0 89, pp. 52 ss. i Dix siècles d'enluminure italienne Vle-XVle siècles), Bibliothèque Nationale, Paris 1984. No 15, pp. $27 \mathrm{ss}$.

${ }^{39} \mathrm{De}$ fet, Garrison (E.B. GARRISON, Studies in the History of Medieval lialian Painting, IV, núms. 3 i 4, Firenze, 1962, pp. 300-303), tol $i$ considerar l'obra italiana $i$, concretanent, pistoiesa, assenyalava que les inicials devien haver estat dissenyades a partir de inodels francesOs (p. 300). Força abans, P. LAUER (Les enluminures romanes des manuscrits de la Bibliothèque Nationale, Paris, 1927, p. 65) I'havia classifical com a Leccionari d'una església del Midi de França, indicant per a les il.lustracions un llunyà ressò de l'estil llemosí. Personalment, m'atreviria a insinuar (de moinent res més que això) una possible relació amb produccions de l'orbita cistercenca (en el sentit topografic del terne), sobretot aquelles que usen la figura humana, combinada amb d'altres elements animals o vegetals, en la composició de les caplletres. Serien obres com els Moralia in lob de Sant Gregori (Dijon, Bibliotheqque Municipale, mss. 168-170 i 173) o unes Epistolae et Sermones de Sant Jeroni (Dijon, Bibliotheque Municipale, ms. 135). Sobre ells, recentment, Yolanta ZALUSKA, L'enluminure et le scriptoriun de Citeaux au XIle siecle (Commentarii cistercienses. "Studia et Documenta", vol. IV), Nuits-Saint-Georges, Abbaye de Cîteaux, 1990, núms. 4 i 6; i Manuscrits enluminés de Dijon ("Corpus des manuscrits enluminés des collections publiques des Departements" 1), Edns. du CNRS, Paris, 1990, núms. 25 i 27. 
ment en què hi havia una certa premura per a confeccionar llibres que poguessin ser posats aviat a disposició de la comunitat i de les seves filials ${ }^{40}$. Aix́, la copia i il.lustració de textos bàsics com la Bíblia o els Moralia de Sant Gregori foren tasques prioritàries, per a les quals és possible que hom recorregués a il.lustradors d'origen anglès, procedencia que seria explicable perque es tracta de la mateixa del tercer abat cistercenc, Stephen Harding, peró també justificable des d'un punt de vista estilístic ${ }^{41}$. Aquests manuscrits, especialment els Moralia, ofereixen un repertori de caplletres caracteritzades per una certa tendencia a la caricatura, tant en les tipologies com en les actituds dels personatges, que vinclen els seus cossos fins a convertir-los en part de les mateixes inicials. De vegades aquests personatges adopten actituds bel.ligerants, armats amb espases, o bé lluiten amb dracs, o es dediquen (tot sovint són monjos) a les tasques agrícoles ${ }^{42}$. Algunes d'aquestes actituds i combinacions són algunes vegades similars a les del Vat. lat. 5730. S'hauria de parlar, doncs, d'una difusió a través de Cîteaux de formules angleses pel sud de França i Catalunya? Cronologicament és justificable. Pero, en cas d'acceptar-ho, es tractaria d'una explicació parcial. L'ús de la figura humana, en combinació amb elements faunístics o vegetals per tal de configurar caplletres ja es troba en aquests indrets amb anterioritat ${ }^{43}$. Valguin com a exemple el Ripoll 52 de l'Arxiu de la Corona

\footnotetext{
${ }^{40}$ Vid. sobre aquest punt, Angiola Muria Romanini, Il "Maestro dei Moralia" e le origini di Citeaux, "Storia dell'arte", 34 (1978), pp. 221-245 (especialment, p. 227). L'autora subratlla l'extrema necessitat que tenien el monestir i les seves filles de llibres, ates que no en posseïen.

${ }^{41}$ A més de l'estudi citat a la nota anterior, entre la nombrosa bibliografia consagrada a la miniatura cistercenca, d'ençà dels clàssics estudis de Charles OURSEL (La miniature du XIIe siecle d l'abbaye de Citeaux d'après les inanuscrits de la Bibliotheqque de Dijon, Dijon, 1926; Miniatures cisterciennes, 1099-1134), Protat, Mâcon, 1960), cal destacar els més recents de Yolanta Zaluska ja citats (vid. nota 33).

${ }^{42}$ Tipus d'imatges que no és gens rar de trobar en manuscrits anglesos. Nornés cal donar una ullada a repertoris il.lustrats, com els de C.M. KAUIIIMANN, Romninesque Manuscripts 1066-1190 ("A Survey of Manuscripts Illuminated in the British Isles" III), ed. by J.J.G. ALEXANDER, Harvey Miller, London, 1975; o be C.R. DODWELL, The Canterbury School of Illumination, 1066-1200, Cambridge University Press, Cambridge, 1954. Al seu tom, quan es considera la il.lustració de manuscrits de les illes britaniques, sobretot amb posterioritat al 1066, cal tenir present la relució aunh la il.lustració nornanda $i$, dins d'aquesta, de centres importants com l'scriptoriuin de Mont Saint-Michel que, pel que fa a les inicials il.lustrades, hereta i fusiona tradicions z.oomòrfiques merovingies, d'entrellaçat franco-saxo, i d'omements vegetals anglo-suxons, tol realitzant-ne una sintesi personal d'ençà del segle $\mathbf{X}$. Sobre aquest centre, Monique DOSDAT, L'enluıninure romane au Mont Saint-Michel, Xe-XIle siẻcles, 8.I., 1991.
}

${ }^{43}$ En realitat, la utilització de la figura humana o animal, a vegades combinades entre si, 
d'Aragó o una sèrie d'obres llemosines ${ }^{44}$. Si més no, aquesta producció "anglo-cistercenca" podria haver reactivat i renovellat unes fórmules que no eren desconegudes al midi.

Tot plegat sembla força complex. És per aixo que cal extreure les dades formals per poder assegurar que les concomitancies entre una o altra obra es deuen a alguna cosa més que a un ambient comú.

Dels personatges del Vat. Lat. 5730 en destaca la fesomia, sobretot en els perfils, angulosos, de front prominent, nas poderós i barbeta punxeguda, arribant a vegades a confegir rostres grotescos. Es tracta, de fet, d'una característica comuna als altres manuscrits catalans contemporanis a què ja hem al.ludit en un parell d'ocasions. Quan no són de perfil, els rostres es representen de tres quarts, $\mathrm{i}$ és aleshores que les similituds amb el Beatus de Torf o l'Evangeliari de Cuixà es fan més estretes. Un tret força comú dels personatges del Vat. lat. 5730 són dues ratlletes paral.leles vora la comissura dels llavis; apareixen només en personatges de perfil. De vegades també, trobem dues línies paral.leles al sotabarba (el personatge a manera d'atlant del fol. $195 \mathrm{v}$. en pot ser un exemple) (fig. 8). Aquests dos trets es donen en un dels pocs perfils que apareix en l'atapeïda composició que il.lustra el miracle dels pans i els peixos de l'Evangeliari de Cuixà (fol. 107 v.) (fig. 9). En aquest mateix manuscrit observem una fórmula identica de traçar els rostres de tres quarts que trobem a l'obra que ens ocupa: llavis a base d'una línia recta, amb marcades comissures $i$ un traç a sota, gairebé en forma d'U per representar el llavi inferior, nas dibuixat amb un traç vertical recte $i$ un de sinuós horitzontal a la part inferior. Comparem qualsevol rostre dels que apareixen a les escenes evangèliques del manuscrit conservat a Perpinyà $i$, per exemple, el dels petits personatges del fol. 127 del Vat. lat. 5730 (fig. 6); la identitat n'és inqüestionable. No acaben aquí els contactes: els colls de les túniques de bona part dels personatges d'un $\mathrm{i}$ altre manuscrit segueixen la mateixa forma bi o trilobulada; sovint, línies paral.leles verticals travessen el tors de les túniques dels personatges. Fins i tot rostres amb alguns trets més atípics dins l'Expositio (la manera de traçar el nas del sant Pau del fol. 175 v.) (fig. 3) tindrien la seva rèplica a

\footnotetext{
per configurar caplletres és una fónnula que es troba a l'àıbit merovingi i que probableınent deriva de tradicions antigues.

${ }^{4}$ Cf. Danielle GabORI-Chopin, La décoration des manuscrits à Saint-Martial de Limoges et en Limousin du IXe cu Xlle siècle ("Mémoires et documents publiés par la Société de l'École des Chartes", 17), Librairie Droz, Paris-Genc̀ve, 1969.
} 
l'Evangeliari (a l'única escena acolorida, a part dels cànons, amb Crist donant l'Evangeli a Sant Joan, al fol. 111 $)^{45}$. Aquestes característiques, que agermanen l'Expositio de la Vaticana i l'Evangeliari de Cuixà, no són gens alienes als il.lustradors del Beatus de Torí: el perfil característic, de faccions punxegudes, les dues ratlles al sotabarba, els colls de túnica lobulats (valguin d'exemple els fols. 55 v., 172 v. del Beatus) (figs. 7 i 5), encara que els rostres de tres quarts del manuscrit de Torí són més greus i més elaborats (semi-cercle a la barbeta, doble línia sota els ulls...) que els tres-quarts reposats i gairebé infantils dels altres dos manuscrits. El rerafons, però, és innegablement el mateix.

Nombroses i molt intimes semblances. Que cal deduir-ne? Sens dubte, que un dels il.lustradors que treballa a l'Evangeliari de Cuixà, probablement no és el mateix que treballa al Vat. lat. 5730, pero que s'ha format en el mateix taller i ambdós actuen d'una manera totalment afi. Els rostres són identics. Els separa, en tot cas, l'extrema rigidesa i seriació de les composicions de l'Evangeliari en comparació amb una certa agilitat de les caplletres del Vat. lat. 5730. De fet, bona part de les divergencies es minimitzen quan es té en compte com són de diferents els paràmetres compositius per a una caplletra i per a escenes amb gran quantitat de personatges. És indubtable que a l'Evangeliari hi treballa més d'un il.lustrador, com ja ho ha assenyalat la historiografia. A vegades, es distingeixen més de dues mans. Personalment, i a primer cop d'ull, la impressió és que potser tot plegat es pot explicar per la tasca només de dos artistes. De totes maneres, ara com ara el que ens interessa és constatar el treball d'una mà molt característica, que realitza una tasca que sembla apressada i que s'encarrega, com a mínim, de les escenes evangeliques, desproveïdes de color, i que curiosament aproximem al que tant vivament acoloreix les inicials del Vat. Lat. $5730^{46}$. La cronologia donada a un i altre manuscrit no desmenteix en absolut la hipotesi ${ }^{47}$. Un altre artista devia il.lustrar els animats càfig. 120

${ }^{45}$ Vegeu la il.lustració reproduïda a J. Gudior., Els llibies il.luminats (op. cit., nota 39),

${ }^{46}$ Coin s'assenyalava abans, difícilınent pol tractar-se del matcix il.lustrador; el de l'Evangeliari de Cuixà economitza línies en els plecs de les vestimentes i geometritza molt les composicions. Vid. la reproducció de la inajor part de composicions de l'Evangeliari a J. GuDIOL, Els llibres il.luininats (op. cit. a nota 39), figs. 110-122.

${ }^{47} \mathrm{Cal}$ laınentar novainent la inanca d'un estudi més profund sobre aquest manuscrit, de sempre considerat català i relacionable aınh altres manuscrits del pais. Encara que no resolgui la situació, confio que la vinculació d'un dels urtistes que hi treballa ainb el del Vat. lat. 5730 
nons de concordança evangelica dels fols. 8-13. Aquest, pel fet de no estar condicionat per unes escenes narratives, se serveix d'un repertori fantàstic i exdtic: elefants a la base de les columnes, peixos, aus, éssers mixtos, figures humanes seminues $i$ atlants, amb mig cos de peix o semi-engolits per un gran peix ${ }^{48}$.

Uns altres trets anatòmics a ressaltar en els personatges del Vat. lat. 5730 són solucions adoptades a les extremitats nues: un petit cercle marca l'articulacio del peu, mentre que dos traços paral.lels recorren longitudinalment cames, cuixes, braços i avantbraços (fols. 67 v., 147 v., 163 i 195 v.) (figs. 1 i 8). La rodoneta a l'articulació del peu és freqüentíssima al Beatus de Torl. Els traços a les extremitats s'insinuen tan sols en alguns dels pocs nus del manuscrit, pero es fan evidents a les figures que apareixen a les arquitectures tigurades de les taules de cànons de l'Evangeliari de Cuixà. La fórmula també és present en un altre codex català que recull diversos escrits relacionats amb Sant Gregori i conservat a l'Arxiu de la Corona d'Arago (Ms. Ripoll 52). A part d'aquest recurs, els rostres dels personatges que, gairebé sempre nus, disposats en combinacions fantàstiques, configuren algunes de les vint-i-nou caplletres en que consisteix la il.lustració del Ripoll 52, presenten també notables analogies amb els que

podrà obrir noves vies. Si més no, que serveixi d'avançada a un estudi més detallat que tinc entro mans.

${ }^{48} \mathrm{~L}$ 'estudi d'aquests cànons (vegeu-ne una il.lustració a J. AINAUD DE LASARTE, La pintura catalana. La fascinació del romanic, Skira-Carroggio, Ginebra-Barcelona, 1989, p. 45) potser podria donar més de si considerant-los en relació amb obres contemporànies, com ara la coneguda com a Segona Bíblia de Sant Marçal de Llemotges (Paris, Bibliotheque Nationale, lat. 8), amb elefants a les taules de concordança, tambe, i que es considera propera al 1100 (vid. D. GABORIT-CHOPIN, La décoration des manuscrits a Saint-Martial, esp. pp. $177-178$ i figs. 95 i 97-103). Una altra semblança prou cridanera, que s'hauria d'intentar clarificar, es troba a les il.lustracions dels cànons evangèlics de la Biblia de Santa Cruz de Coimbra (Porto, Bibl. Mun. ins. 32), semblança ja assenyalada recentment per J. YARZA (La miniatura románica, p. 22, nota 146). D'altra banda, podem recordar que els canons de la Biblia de Ripoll (fols. 363-366) contenen figures d'atlants i de personatges fent de base a les columnes (fols. 364-364 v.), i que el Beatus, dbviament desproveït de cảnons de concordança evangèlica usa, en canvi, un tipus d'estructura similar per aixoplugar les Taules del nom i el nombre de l'Anticrist (fol. 142). De forna molt rudimentària i tímida, animals $\mathrm{i}$ testes humanes ocupaven algunes bases $\mathrm{i}$ capitells de les arquitectures figurades de les taules de concordança de l'Evangeliari de la catedral de Girona (Tresor de la Catedral, núm. 48), datable, en base a dades paleografiques i codicològiques a la primera meitat de l'XI (Gabriel ROURA, L'Evangeliari carolingi de la catedral de Girona. Segle XI. Notes codicoldgiques i paleografiques, "Anuari de l'Institut d'Estudis Gironins", XXV-2 (1981), pp. 349-371 i Anna ORROLS, Evangeliari de la Catedral de Girona, a Museu d'Art de Girona. Tresor de la Catedral ("Catalunya Roınànica" XXIII), Fundació Enciclopèdia Catalana, Barcelona, 1988, pp. 183187). 
fins ara han estat descrits ${ }^{41}$. En canvi, les comparacions establertes a vegades amb el Ms. 26 del Museu Episcopal de Vic s'han de limitar a una sola il.lustracióso.

Per posar fi als aspectes formals, i tot sortint del restringit àmbit català, és oportú assenyalar que la solució de traçar línies corbes paral.leles a les extremitats dels personatges es detecta en alguna obra del midi francès, com la Bíblia conservada a la Biblioteca Nacional de París (ms. lat. 52 i 135), que es considera realitzada a Moissac o en algun indret del sud-oest de França el darrer quart del segle $\mathrm{XI}^{\boldsymbol{s}^{\prime}}$. Aquests lligams amb produccions

\footnotetext{
${ }^{49}$ El manuscrit reuncix la Vita Gregorii de Joan Diaca, les Homilies de Sant Gregori sobre Ezequiel $i$ el Comentari sobre el Càntic dels Càntics de sant Gregori. No acaba de ser unànime la seva datació, i paledgrafs $\mathrm{i}$ historiadors de l'art semblen inarxar per vies divergents. $P$. KLEIN (Date et scriptorium, pp. 96-97, 102) precisaınent a partir de les analogies, d'altra banda ja assenyalades per historiadors anteriors, unb inicials de la Bíblia de Rodes, amb el Ms. 26 del Muscu Episculal de Vic, l'Homiliari de Girona i, ja del XII, l'Evangeliari de Cuixà, proposava una data dins la scgona incitat de l'XI. Malgrat que a la scva tesi doctoral M.E. IBARBBURU (La minialura romkinica calcalana, vol. I, pp. 106-135) l'incloïa entre les obres produïdes durant l'ubadiat d'Oliha, cll un altre estudi (El Ripollès ("Catalunya Romànica", X), pp. 286-290) considera la possihilitat que fos postcrior a la mort d'Oliba, tot reafirmant els paral.lels estilistics ja assenyalats per Klein aınb les dues Bỉblics i afegint-hi el Beatus de Tori, entenent els punts de contacte entre totes aquestes obres com a "...detalls que són fruit d'una inanera general de resoldre problenes fornals detenninuts en un moment concret...". Des de la paleografia, però, les dates que es proposen són molt inés altes; MUNDO (La cultura artística, p. 154) el considera de la segona decada de l'XI -"a partir del 1010"-.

${ }^{50}$ Es tracta de la caplletra $Q$ del fol. 171, fonnada per dos personatges, presumiblement Job i la Paciencia, que trepitgen una ligura femenina, nua de cintura cap ainunt, que $s$ 'ha identificat anh la Ira. És interessant assenyalar que aquesta imatge, a part de no tenir res a veure amb el text que acompanya, tampoc no concorda estilisticamnent amb la resta de les que il.lustren cl manuscrit, del qual tampoc no s ha pogut detenninar amb exactilud si ha sorgit de Ripoll o de Vic. Cal destacar l'anulogia, assenyalada per més d'un autor, entre l'estil d'aquesta caplletra i el de les imatges del voluin III de la Biblia de Rodes. I tampoc no deixa de ser suggestiu -encara que potser no vol dir res- que trobem una imatge femenina seminua $\mathrm{i}$ amb cabellera, anàloga a la del fol. $209 \mathrm{v}$. del manuscrit vaticà que aquí s'estudia. Sobre l'exemplar del Muscu Episcopal de Vic (Ins. 26 (I)), vid. Maria Eugenia IBARIJURU ASURMENDI, Moralia in lob de Sant Gregori, a Osona II "Catalunya Roınànica", III), Barcelona, 1986, pp. 763-766; i, més recentment, Miquel S. GROS I PUJOL, Museu Episcopal de Vic. Pintura i escultura roincinica, Ausa, 14, Sabadcll, s.d., múın. 14, p. 25.

Considerar l'intercanvi, documentat, d'escribes entre les seus catedralícies de Girona i Vic potser podria aclarir alguna qüestió que afectés aquesta imatge i altres, com el foli solt conegut com a "Miniatura del Crist Mestre" que cy conserva al Muscu Episcopal de Vic i que cal vincular amb l'anomenat Homiliari de Beda, procedent de Sant Fèlix de Girona i conservat al Museu d'Ant d'aquella ciutat.

${ }^{31}$ Es pot observar en els personatges acrobàticament disposuts del fol. 49 del lat. 52 (vid. P. LAUER, Les enluminures romanes des incinuscrils de la Bibliotheque Nationale, Paris, 1907. pl. XXXVII, fig. 1). Un recent i escarit llibrct (Chantal FRAISSE, $L$ 'enluoninuie à Moissac aux Xle et XIle sieccles, s.I. 1992) dóna a aquesta bíblia una cronologia de principis del eogle XII (vid. pp. 6 i 23). Vegeu laınbe, dins d'aquesta breu aproximnació, algun exemple de representació de personatges enınig de tiges $i$ mossegats per dracs. És el cas d'un manuscrit tambó de
} 
miniades del sud de França en general i, concretament, de Moissac serien perfectament explicables en virtut de les estretes relacions existents d'ençà del segle $\mathrm{X}$ entre centres religiosos d'aquest indret $\mathrm{i}$ catalans ${ }^{52}$.

Queda, en darrer terme, l'aspecte ornamental. El Vat. lat. 5730 usa un tipus d'ornamentació consistent majoritàriament en l'ús de determinats elements fitomorfics amb poques variants, on predomina un tipus de fulla que, cargolant-se sobre si mateixa, forma una mena de tirabuixó i unes excrecencies fistonejades. En ocasions les tiges s'entrellacen (fols. 127, 185 v.) (fig. 6) en esquemes més geometritzants. Alguns fusts s'omplen d'una banda perlada (fols. $163,185 \mathrm{v}$.) ${ }^{53}$. Algunes d'aquestes fórmules, tot i que algunes vegades de manera més escarida, són presents en algunes inicials del Beatus de Torf (A dels fols. 55 v., 75 v., amb fulles a manera de tirabuix6 (fig. 7); o la gran $I$ del fol. $23 \mathrm{v}$. amb motius festonejats a l'interior del pal, comparables als de la $P$ del fol. 127 del Vat. lat. 5730...) (fig. 6)

\section{Conclusió}

Tot i que era necessari passar per tedioses -pero d'altra banda inevitables- disquisicions de caire formal, ara cal recapitular. En virtut de tot el que ha estat plantejat fins aqui, crec que ha de qüestionar-se l'absolut protagonisme que s'atribueix a l'scriptorium de Ripoll en el terreny de la il. lustració, i no pas en una època en que aquest sembla haver estat indiscu-

principis del XII, realitzat a Moissac (Paris, Bihliothèque Nationale, lat. 2154, fol. 55v) (vid. ibid., p. 4). Alguns altres indicis $\mathrm{i}$ obres procedents de Moissac (que tractaré en un altre estudi) indiquen que hi hagué contactes en el terreny de la il.lustració entre cls escriptoris de l'abadia llenguadocianu i de la scu gironina.

\$2És obligat en aquest punt citar les aportacions d'Anscari MUNDO (Moissac, Cluny et les mouvements monastiques de l'Est des Pyrénées du Xe au XIle siècle) i Joan AINAUD DI: LASARTF: (Moissac el les monastères catalans, de la fin du Xe au débul du Xlle siècle) al Col.loqui Intemacional de Moissac del maig del 1963: Moissac et /'Occident au XIe siècle. Actes du Colloque Intemational de Moissac, Ed. Privat, Toulouse, 1964, pp. 229-251 i 545549 respectivament [també publicades a "Annales du Midi" 75, núın. 64 (oct. 1963)].

${ }^{53}$ M.E. IBARBURU (Expositio, p. 330), descriu detalladament aquests recursos omamentals. Els considera majoritàriaınent explicables a partir de la tradició ripollesa, qüestió que penso que es pot matisar, ja que tant pel que fa al traç coın pel que fa al color, els lligams són majors amb inicials del Beatus de Tori que no pas amb les dels inanuscrits ripollesos que s'esmenten en el citat estudi. D'altra handa, aquesta matcixa autora creu trobar afinitats amb els emprats a la portada ripollesa, no tan sols en els motius omanentals de caire vegetal (que no neguem) sinó taınbé en el tipus de plecs de les vestiınentes dels personatges, qüestió, em penso, molt inenys convineent. 
tible, sinб en els anys posteriors a la mort d'Oliba. I aleshores considerar l'empenta que pot tenir un taller com el de Girona a l'entorn del 1100 , quan és capaç d'il.lustrar una obra com el Beatus de Torí. L'existencia d'obres com l'Evangeliari de Cuixà, l'Homiliari "de Beda" i la il.lustració de la Bíblia de Rodes, culminada fora de Ripoll, aconsellen, com ja s'indicava a les primeres pàgines de l'estudi, decantar el protagonisme cap a d'altres indrets.

La intenció no és tant provar que el Vat. Lat. 5730 no és ripolles com qüestionar aquest origen. Perque, al cap i a la fi, la mobilitat dels llibres, dels copistes i dels il.lustradors poden fins i tot convertir, de vegades, en absurdes consideracions d'aquesta mena ${ }^{54}$. Si de cas, quines serien les alternatives a Ripoll? L'interès, pero també algun indici, apuntaven a Girona, com ja s'ha dit. Pero de moment no es pot assegurar, encara que el context de les imatges del comentari pauls porta cap a uns altres àmbits que no són Ripoll (Girona, Rodes i, si és que l'Evangeliari que en porta el nom s'hi va il.lustrar, Cuixà). L'escriptori de la catedral de Girona devia ser, si no el més important, si un dels més significatius i actius del pas del segle XI al XII, i durant unes decades d'aquesta centúriass. També és possible que hi anessin i s'hi incorporessin escribes i il.lustradors ripollesos. S'està estudiant la tasca dels cal.ligrafs que hi treballaren ${ }^{56}$. Els resultats poden contribuir a confirmar o desmentir hipdtesis relatives a la il.lustracio. I, viceversa, possiblement l'estudi del capitol artístic dels manuscrits gironins pot complementar-se amb el de caire codicologic i paleogràfic ${ }^{57}$.

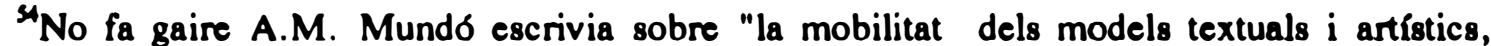
com també de copistes i il.luminadors, més enllà de la cadira de l'escriptori que se'ls assigna sovint." (La cultura artistica, p. 145)

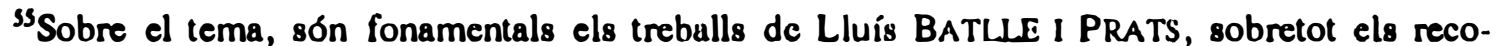
llits a La cultura a Girona de l'Edat Mitjana al Renaixement, CSIC-Diputació Provincial de Girona (Col. "Monografies de l'Institut d'Estudis Gironins", 7), Girona, 1979. Puntualitzacions més recents a l'estudi ja tants cops citat d'A.M. MUNDO, La cultura artistica, pp. 141 . 147.

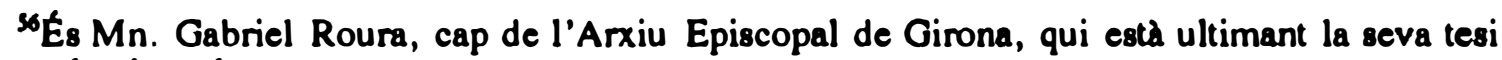
doctoral sobre el tema.

${ }^{57}$ Crec molt interessant el fet que un manuscrit que des de sempre s'havia considerat vigata hagi estat recentment adscrit al taller de Girona. Es tracta del Missale Parvum (MEV, ms. 71). Vegeu respecte d'això, M. dels S. Gros I Pujol, Museu Episcopal, núm. 16, p. 27. A l'estudi que l'havia precedit encara es considerava produït a Vic (vid. Rosa ALCOY I PEDROS, Missale Panum. Textus Quatuor Evangeliarum, a Osona II ("Catalunya Romànica" III), Barcelona, 1986, pp. 772.775.
} 
En cas de ser realment ripolles el Vat. lat. 5730, quedaria clar un lligam prou directe entre els tallers de Ripoll i Girona, ateses les innegables concomitàncies existents entre el manuscrit que ens ocupa i el Beatus, codexs d'altra banda de cronologia molt aff: tothom accepta una data dins la primera meitat del XII per a l'Expositio de la Vaticana. El Beatus, en canvi, sol situar-se prop del 1100 , tot i que probablement se l'ha d'endinsar al primer quart del segle XII ${ }^{58}$.

D'allo que no tinc cap dubte és de l'estretíssima relació existent entre el Vat. lat. 5730 i l'Evangeliari de Cuixà, que crec demostrada. Aixo ens guia de nou fora de Ripoll $i$ aporta noves dades a l'estudi d'aquest darrer manuscrit, que sembla la frontissa que permet d'interrelacionar diferents obres: ofereix contactes amb el Vat. lat. 5730, amb l'Homiliari de Sant Felix de Girona, amb el Beatus de Torl, amb els dos darrers volums de la Bíblia de Rodes i, potser, amb obres llemosines i d'altres de realitzades a Cîteaux.

Quant al Paris 794, s'hauria d'establir quin tipus de relacio l'emparenta amb el Vat. 5730, un cop admeses les similituds en les il.lustracions. Si el Paris 794 fos -penso que improbablement- un manuscrit catala, contribuiria a engrossir un catàleg no gaire ampli, al qual sempre convé una nova atribucio. En el cas que fos italia, s'hauria d'entendre com la interpretacio, possiblement, de models procedents de França, la qual cosa explicaria algunes solucions coincidents amb les de manuscrits catalans que també haguessin estat receptors de fórmules ultrapirinenques; si és del midi francès, reforçarà uns lligams que ja s'han revelat evidents en d'altres casos (i que pensem que s'han de definir i concretar, a través d'obres sortides de centres com Cîteaux, Llemotges o Moissac). Recordant la mobilitat tant dels codexs com dels seus artifexs, $M$. Mund 6 aconsellava "no exloure cap hipotesi raonable, fins $i$ tot la de creure que el ms. Vat. 5730 i el Breviari Ripolles de París, 742, foren escrits per monjos de Sant Víctor de Marsella nouvinguts a reforçar la comunitat de Ripoll i que, en canvi, un ripolles tradicional anés a decorar el Beatus romànic de Girona." Hi estic ben d'acord exceptuant el fet de qualificar de "ripolles tradicional" aquell qui il.lustrà el Beatus de Torr. A banda de que hi treballa més d'un miniaturista, les il.lustracions d'aquest codex tenen més relacio amb obres no ripolleses

\footnotetext{
${ }^{38}$ Cf. J. YARZA, La ininiatura roincinica, p. 22 i Beal de Tori, a Calalunva inedieval (op. cit.), p. 83. Tambe ho afirma aixi, pel que fa a l'escriptura, A.M. MUNDo (La cultura artistica, p. 145).
} 
que no pas amb les sortides d'aquell scriptorium. I si el Vat. 5730 fos obra de marsellesos, aleshores la relació del Beatus amb una tradició ripollesa d'il.lustració s'esvairia pràcticament del tot ${ }^{39}$.

\section{RÉSUMÉ}

La Bibliothèque Vaticane garde, sous la signature Vat. lat. 5730,

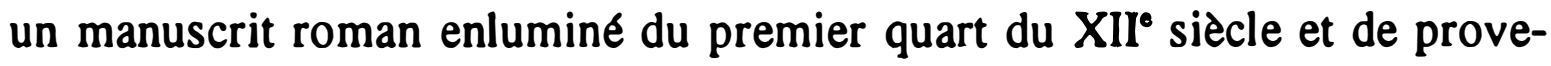
nance catalane qui contient le commentaire de Florus de Lyon aux épîtres de Saint Paul. On considere qu'il fut copié et enluminé à l'abbaye de Santa Maria de Ripoll en référence au document du roy Lothaire (982) copié sur le dernier folio. Cette étude analyse les rapports existant entre les illustrations du Vat. 5730 et celles d'autres manuscrits romans catalans, comme le Beatus de Turin et, surtout ces de l'évangéliaire de Cuixà (Perpignan, Bibliotheque Municipale, ms. 1) avec lesquelles les rapports sont plus étroits. Aucun de ces manuscrits n'ayant été illustré à Ripoll, on suggere que peutêtre le Vat. 5730 ait pu être exécuté dans un autre scriptorium catalan (Girona?) et tranféré après à Ripoll où le document a pu y être ajouté. Des rapports avec les manuscrits étrangers -l'un d'eux (Paris, Bibliotheque Nationale, ms. lat. 794) peut-être italien, et d'autres enluminés à Cîteaux au commencement du XII ${ }^{\circ}$ siecle- sont aussi considérés.

\section{SUMMARY}

The Vatican Library keeps, under signature Vat. lat. 5730, a Catalan romanesque illustrated manuscript from the first quarter of XIIth century containing an Expositio on the pauline epistles by Florus of Lyon. It's considered that the manuscript was copied and illustrated in the abbey of Santa Maria de Ripoll, because of a document of king Lothair (982) in favour of this monastery copied on the last folio. This study analyzes the

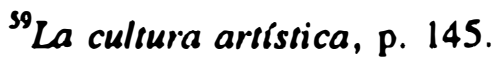


relationship between tha Vat. 5730 illustrations and those of other catalan romanesque manuscripts, such as the Turin Beatus and, specially, the Cuixà Gospel book (Perpinyà, Bibliotheque Municipale, ms. 1) with which analogies are closer. As none of them has been illustrated in Ripoll, it is suggested that perhaps Vat. 5730 could have been produced in other catalan scriptorium (Girona?) and then removed to Ripoll, where the document could have been added. Relationships with foreign manuscripts -one of them (Paris, Bibliothèque Nationale, ms. lat. 794) perhaps italian, and others illustrated in Cîteaux at the beginning of the XIIth century-, are also considered. 